\title{
An evolutionary finance model with a risk-free asset
}

DOI:

10.1007/s10436-020-00370-4

\section{Document Version}

Accepted author manuscript

Link to publication record in Manchester Research Explorer

\section{Citation for published version (APA):}

Belkov, S., Evstigneev, I. V., \& Hens, T. (2020). An evolutionary finance model with a risk-free asset. Annals of Finance. https://doi.org/10.1007/s10436-020-00370-4

\section{Published in:}

Annals of Finance

\section{Citing this paper}

Please note that where the full-text provided on Manchester Research Explorer is the Author Accepted Manuscript or Proof version this may differ from the final Published version. If citing, it is advised that you check and use the publisher's definitive version.

\section{General rights}

Copyright and moral rights for the publications made accessible in the Research Explorer are retained by the authors and/or other copyright owners and it is a condition of accessing publications that users recognise and abide by the legal requirements associated with these rights.

\section{Takedown policy}

If you believe that this document breaches copyright please refer to the University of Manchester's Takedown Procedures [http://man.ac.uk/04Y6Bo] or contact uml.scholarlycommunications@manchester.ac.uk providing relevant details, so we can investigate your claim.

\section{OPEN ACCESS}




\title{
An Evolutionary Finance Model with a Risk-Free Asset
}

\author{
Sergei Belkov • Igor V. Evstigneev • \\ Thorsten Hens
}

Received: date / Accepted: date

\begin{abstract}
The purpose of this work is to develop an evolutionary finance model with a risk-free asset playing the role of a numeraire. The model describes a market where one risk-free and several "short-lived" risky assets (securities) are traded in discrete time. The risky securities live one period, yield random payoffs at the end of it, and then are re-born at the beginning of the next period. The main goal of the study is to identify investment strategies that make it possible for an investor to "survive" in the market selection process. It is shown that a strategy of this kind exists, is in a sense asymptotically unique and can be described by a simple explicit formula amenable for quantitative investment analysis.
\end{abstract}

Keywords Evolutionary finance - Survival portfolio rules · Risk-free asset · Numeraire · Random dynamical systems

Financial support from the Swiss National Science Foundation grant 149856 "Behavioural Financial Markets" (2014-2016) is gratefully acknowledged. The authors are grateful to Rabah Amir and Klaus R. Schenk-Hoppé for helpful comments and fruitful discussions.

S. Belkov

Mathematics Department, University of York, York, UK

E-mail: serg.belkov@gmail.com

I. V. Evstigneev

Economics Department, University of Manchester, Manchester, UK

E-mail: igor.evstigneev@manchester.ac.uk

T. Hens (Corresponding Author)

Department of Banking and Finance, University of Zurich, and Swiss Finance Institute

Plattenstr. 32, 8032 Zurich, Switzerland

E-mail: Thorsten.Hens@bf.uzh.ch

T. Hens

Department of Finance and Management Science, Norwegian School of Economics, Bergen, Norway

T. Hens

Department of Economics, University of Lucerne, Lucerne, Switzerland 
JEL classification C73 $\cdot$ D53 $\cdot$ G11 $\cdot$ D58

\section{Introduction}

Evolutionary finance deals with stochastic dynamic models of financial markets with endogenous asset prices determined by short-run equilibrium of supply and demand. Equilibrium is formed consecutively in each time period in the course of interaction of investment strategies (portfolio rules) of competing market participants. The main focus in the field is on questions of "survival and extinction" of investment strategies in the market selection process. Survival in this context means a possibility of keeping a strictly positive, bounded away from zero share of market wealth over an infinite time horizon. Key results in this field demonstrate the existence and asymptotic uniqueness of a survival portfolio rule, that guarantees survival with probability one of the investor using it, irrespective of the strategies employed by the other investors in the market.

Modelling frameworks studied in evolutionary finance combine the ideas of behavioural economics and finance (Tversky and Kahneman [68], Shleifer [64], Shiller [63], Thaler [66], Bachmann et al. [5]), evolutionary game theory (Weibull [73], Vega-Redondo [69], Samuelson [57], Hofbauer and Sigmund [35], Kojima [39], Gintis [31]), stochastic games (Shapley [61], Dynkin [19], Haurie et al. [34], Kifer [38], Neyman and Sorin [55], Vieille [70-72]), stochastic evolutionary games (Foster and Young [26], Fudenberg and Harris [27], Cabrales [15], Germano [30]), games of survival (Milnor and Shapley [53], Shubik and Thompson [65], Borch [8], Karni and Schmeidler [36],) and capital growth theory (Shannon [60], Kelly [37], Latané [41], Breiman [13], Algoet and Cover [1], Hakansson and Ziemba [32], Cover [16], Dempster et al. [18], MacLean et al. [49], Kuhn and Luenberger [40], Ziemba and Vickson [75], MacLean and Ziemba [50], and others; for a textbook treatment of capital growth theory see [22], Ch. 17. Surveys of studies related to the present line of research on evolutionary finance are provided in the papers [20,23]. An elementary textbook introduction to the field can be found in [22], Ch. 20 .

For research on topics related to evolutionary finance but distinct from those in the present paper, see Bottazzi and Dindo [9,10], Bottazzi et al. [11, 12], Brock et al. [14], Coury and Sciubba [17], Farmer [24], Farmer and Lo [25], Lo [43-46], Lo et al. [47], Sciubba [58,59], and Zhang et al. [74].

There are two fundamental types of models in evolutionary finance: with short-lived (one-period) assets and long-lived dividend-paying assets, see, e.g., Amir et el. [3] and Amir et el. [2], respectively. In the present paper we deal with a model of the former type. Short-lived assets represent standardized contracts that are sold and purchased at the market prices at the beginning of a time period $[t-1, t]$ and by the end of it yield payoffs depending on random events that might occur by time $t$. The payoffs may come from the contract seller or from other sources. Typical examples include contracts involving production or delivery of a specific amount of a commodity, raw material or en- 
ergy, contracts between wholesaler and retailer, derivative securities, service and insurance contracts, etc.

Up to now the majority of studies in the field of evolutionary finance have been concerned with the analysis of models where all the traded assets are purely risky. Here, "purely risky" means that the asset price is random, and moreover, endogenous: it is determined by the whole strategy profile of all the market participants as a result of a short-run equilibrium of supply and demand. In this paper we develop a model in which one asset is risk-free in the sense that its price is exogenous (and can be normalized to one). It plays the role of a numeraire through which all the other asset prices and payoffs are expressed.

Models of financial markets with a risk-free asset serving as a numeraire play important roles in various branches of financial economics and mathematical finance. One has to point, first of all, to Markowitz's [51] meanvariance portfolio analysis, Capital Asset Pricing Model (Sharpe [62], Lintner [42], Mossin [54]), fund separation theorems (Tobin [67]) and derivative securities pricing (e.g. Harrison and Kreps [33], Geman et al. [29], Björk [7], and Benninga et al. [6]). By introducing a numeraire in the model, one makes it possible to reduce the number of the sources of financial risk that have to be accounted for. Frameworks of this kind typically lead to a more transparent theory and significant computational simplifications. Holdings of a risk-free security are often, and in particular in the model at hand, measured in terms of unit of account (cash). Of course interest rates for lending and borrowing might fluctuate in time randomly, but it is often reasonable to assume that cash is "less risky" in comparison with other traded assets, such as stock, and regard it as a proxy for a hypothetical risk-free asset. This approach is widely used in quantitative investment analysis, e.g. portfolio efficiency tests: Jensen's, Sharpe's, and others, see e.g. Luenberger [48]. We emphasize that as long as the price of the risk-free asset, which in our setting is normalized to 1 , is exogenous (in contrast with the prices of all the other assets), this asset does not bear endogenous market risk.

An important characteristic feature of our modeling approach is that the assets' payoffs are assumed to be scalable. They depend linearly on the total amount of cash in the bank accounts of all the market participants, which makes the numeraire in a sense invariant under redenominations. If the asset prices and payoffs grow in scale, the total amount of cash needed for the system to function has to grow accordingly. To simplify matters we assume here that there is no currency outside banks, which is, in relative terms, close to reality.

In the framework of the model at hand, we obtain the following results. We construct a survival strategy and establish its asymptotic uniqueness within a certain natural class of portfolio rules. Thereby we achieve in the present context those goals which are regarded as the basic ones in studies on evolutionary finance.

An earlier attempt to build an evolutionary finance model with a risk-free asset was undertaken in [21]. There are substantial distinctions between that study and the present one, among which the most notable ones are as follows. 
The model in [21] describes a market with long-lived (rather than short-lived) dividend-paying assets. Although it is also assumed that the dividends are scalable, they are supposed to depend linearly on the total market wealth, rather than total cash supply. Furthermore, only local evolutionary stability results, rather than global ones, are obtained, so that the fundamental goals typically considered in evolutionary finance are achieved only partially. Finally, the model proposed in [21] required specific new techniques for its analysis, while here we derive our results from those obtained in Amir et al. [3] in the context of purely risky assets, which simplifies proofs substantially.

The remainder of this paper is organized as follows. Section 2 describes the model, Section 3 states the results, and the Appendix provides their proofs.

\section{The Model}

There are $N \geq 2$ investors (traders) acting in a market where $K \geq 2$ risky assets (securities) $k=1,2, \ldots, K$ and a risk-free asset $k=0$ are traded. A portfolio of investor $i$ at date $t=0,1, \ldots$ is characterized by a vector $x_{t}^{i}:=$ $\left(x_{t, 0}^{i}, x_{t, 1}^{i}, \ldots, x_{t, K}^{i}\right) \in \mathbb{R}_{+}^{K+1}$ where $x_{t, k}^{i}$ indicates the amount of "physical units" of asset $k=0,1, \ldots, K$ in the portfolio $x_{t}^{i}$. The coordinates of $x_{t}^{i}$ are nonnegative: short sales are ruled out. We denote by $p_{t}=\left(p_{t, 0}, \ldots, p_{t, K}\right) \in \mathbb{R}_{+}^{K+1}$ the vector of the market prices of the securities. For each $k=1, \ldots, K$, the coordinate $p_{t, k}$ stands for the price of one unit of asset $k$ at date $t$. The scalar product $\left\langle p_{t}, x_{t}^{i}\right\rangle:=\sum_{k=0}^{K} p_{t, k} x_{t, k}^{i}$ expresses the market value of investor $i$ 's portfolio at date $t$. The prices $p_{t, 1}, \ldots, p_{t, K}$ of the risky assets $k=1,2, \ldots, K$ are determined endogenously as a result of a short-run equilibrium over each time period $[t-1, t)$ as described below. The price $p_{t, 0}$ of the risk-free asset $k=0$, which can be interpreted as cash, is exogenous. We will assume that it is normalized to one: $p_{t, 0}=1$. This is the reason why asset $k=0$ is called risk-free. However, the interest rate for cash, which we introduce below, might be random and time dependent.

Random factors influencing the market are described in terms of an exogenous stochastic process $s_{1}, s_{2}, \ldots$ with values in a measurable space $S$. The random element $s_{t}$ in the space $S$ represents the "state of the world" at date $t$. We will denote by $s^{t}:=\left(s_{1}, \ldots, s_{t}\right)$ the history of the process $\left(s_{t}\right)$ up to time $t$. The price vectors $p_{t}$ and the portfolio vectors $x_{t}^{i}$ depend on $s^{t}$ :

$$
p_{t}=p_{t}\left(s^{t}\right), x_{t}^{i}=x_{t}^{i}\left(s^{t}\right)
$$

All functions of $s^{t}$ considered in this paper are assumed to be measurable.

It is assumed that the total amount of each risky security $k=1,2, \ldots, K$ available in the market at date 0 is some given number $V_{0, k}>0$ and in each subsequent time period $t=1,2, \ldots$ it is $V_{t, k}\left(s^{t}\right)>0$. There are no exogenously set limits for the total amount of the risk-free asset $k=0$ (cash). We will use this asset as a numeraire and express the market values of all the assets in terms of this numeraire. Holdings $x_{t, 0}^{i}$ of the risk-free security in the portfolios 
$x_{t}^{i}=\left(x_{t, 0}^{i}, x_{t, 1}^{i}, \ldots, x_{t, K}^{i}\right)$ of investors $i=1,2, \ldots, N$ are regarded as balances in their bank accounts with some given interest rate $\beta_{t}=\beta_{t}\left(s^{t}\right) \geq 0$. All the money in the system is supposed to be deposited with the bank accounts of the market participants, so that

$$
\bar{w}_{t}:=\sum_{i=1}^{N} x_{t, 0}^{i}
$$

is the total amount of money at date $t$.

Assets $k=1,2, \ldots, K$ live for one period. They are traded at the beginning of each period $[t, t+1)$ and yield payoffs $A_{t+1, k}$ at the end of it; then the cycle repeats. The payoffs $A_{t+1, k}$ depend linearly on the history of states of the world $s^{t+1}$ and on the ("narrow") money supply $\bar{w}_{t}$ at date $t$ :

$$
A_{t+1, k}=a_{t+1, k}\left(s^{t+1}\right) \bar{w}_{t} .
$$

The linear dependence of $A_{t+1, k}$ on $\bar{w}_{t}$ postulated in (2) expresses the idea of scalability of the asset payoffs and the relative nature of the numeraire value. The functions $a_{t, k}\left(s^{t}\right), k=1,2, \ldots, K$, satisfy

$$
\sum_{k=1}^{K} a_{t, k}\left(s^{t}\right)>0 \text { for all } t, s^{t}
$$

which means that in each random situation at least one of the assets $k=$ $1,2, \ldots, K$ gives a strictly positive payoff (as long as $\bar{w}_{t}>0$ ).

At date $t=0$ investors have initial endowments $w_{0}^{i}>0(i=1,2, \ldots, N)$. These initial endowments form the traders' budgets at date 0 . Trader $i$ 's budget at date $t \geq 1$ is

$$
w_{t}^{i}:=\left\langle A_{t}, x_{t-1}^{i}\right\rangle=\sum_{k=0}^{K} A_{t, k} x_{t-1, k}^{i}
$$

where

$$
A_{t}:=\left(A_{t, 0}, \ldots, A_{t, K}\right) \text { and } A_{t, 0}:=1+\beta_{t} .
$$

The budget is formed by the payoffs

$$
A_{t, k} x_{t-1, k}^{i}=a_{t, k} \bar{w}_{t-1} x_{t-1, k}^{i}
$$

of the risky assets $k=1, \ldots, K$ contained in the yesterday's portfolio $x_{t-1}^{i}$ of investor $i$ and the amount of money $\left[1+\beta_{t}\left(s^{t}\right)\right] x_{t-1,0}^{i}$ in the bank account of this investor at the beginning of the time period $[t, t+1)$. The budget $\left\langle A_{t}, x_{t-1}^{i}\right\rangle$ is re-invested in the assets available at date $t$, which yield, in turn, the payoffs $A_{t+1, k}, k=1, \ldots, K$, and interest with the rate $\beta_{t+1}$ at the next date $t+1$. Dynamics of this kind reflects features of markets where one-period contracts related to various kinds of real assets (e.g., energy or natural resources, products of agriculture, real estate, etc.) are traded. 
For each $t \geq 0$, each trader $i=1,2, \ldots, N$ selects a vector of investment proportions $\lambda_{t}^{i}:=\left(\lambda_{t, 0}^{i}, \ldots, \lambda_{t, K}^{i}\right)$ according to which he/she plans to distribute the available budget between assets. Vectors $\lambda_{t}^{i}$ belong to the unit simplex

$$
\Delta^{K+1}:=\left\{\left(b_{0}, \ldots, b_{K}\right) \in \mathbb{R}_{+}^{K+1}: b_{0}+\ldots+b_{K}=1\right\} .
$$

The investment proportions at each date $t \geq 0$ are selected by the $N$ traders simultaneously and independently (so that we deal here with a simultaneousmove $N$-person dynamic game). They represent in the game under consideration the players' actions or decisions. For $t \geq 1$, these decisions might depend, generally, on the history $s^{t}=\left(s_{1}, \ldots, s_{t}\right)$ of the process of states of the world and the history of the game

$$
\lambda^{t-1}:=\left(\lambda_{l}^{i}\right), i=1, \ldots, N, l=0, \ldots, t-1,
$$

containing information about all the previous actions of all the players. A vector $\Lambda_{0}^{i} \in \Delta^{K+1}$ and a sequence of measurable functions $\Lambda_{t}^{i}\left(s^{t}, \lambda^{t-1}\right), t=$ $1,2, \ldots$, with values in $\Delta^{K+1}$ form a portfolio rule, or an investment (trading) strategy $\Lambda^{i}$ of trader $i$, according to which trader $i$ selects investment proportions at each date $t \geq 0$. This is a general game-theoretic definition of a pure strategy, assuming full information about the game history, including the players' previous actions and the knowledge of all the past and present states of the world. In the class of such general portfolio rules, we will distinguish those for which $\Lambda_{t}^{i}$ depends only on $s^{t}$, and not on the market history $\lambda^{t-1}$. Such portfolio rules will be called basic.

Suppose each investor $i$ at date 0 has selected investment proportions $\lambda_{0}^{i}=\left(\lambda_{0,0}^{i}, \ldots, \lambda_{0, K}^{i}\right) \in \Delta^{K+1}$. Then the amount invested in a risky asset $k=1,2, \ldots, K$ by trader $i$ will be $\lambda_{0, k}^{i} w_{0}^{i}$, and the total amount invested in asset $k$ will be equal to $\sum_{i=1}^{N} \lambda_{0, k}^{i} w_{0}^{i}$. The equilibrium price $p_{0, k}$ of each risky asset $k$ can be determined from the equations

$$
p_{0, k} V_{0, k}=\sum_{i=1}^{N} \lambda_{0, k}^{i} w_{0}^{i}, k=1,2, \ldots, K .
$$

On the left-hand side of (7), we have the total value, expressed in terms of the prevailing price $p_{0, k}$, of the assets of the $k$ th type purchased by the market participants at date 0 (recall that the amount of each asset $k=1, \ldots, K$ at date 0 is $\left.V_{0, k}\right)$. On the right-hand side, we have the total sum of money invested in asset $k$ by all the $N$ investors.

The investors' portfolios $x_{0}^{i}=\left(x_{0,1}^{i}, \ldots, x_{0, K}^{i}\right), i=1,2, \ldots, N$, at date 0 can be determined from the equations

$$
x_{0, k}^{i}=\frac{\lambda_{0, k}^{i} w_{0}^{i}}{p_{0, k}}, k=1,2, \ldots, K, i=1, \ldots, N,
$$

meaning that the current market value $p_{0, k} x_{t, k}^{i}$ of the $k$ th position of the portfolio $x_{t}^{i}$ is equal to the fraction $\lambda_{0, k}^{i}$ of the trader $i$ 's investment budget $w_{0}^{i}$. 
The 0th position $x_{0,0}^{i}$ of the portfolio $x_{0}^{i}$, i.e., the amount of money deposited by investor $i$ with the bank account, is given by

$$
x_{0,0}^{i}=\frac{\lambda_{0,0}^{i} w_{0}^{i}}{p_{0,0}}=\lambda_{0,0}^{i} w_{0}^{i},
$$

where $p_{0,0}=1$.

Suppose now that all the investors have chosen their vectors of investment proportions $\lambda_{t}^{i}=\left(\lambda_{t, 0}^{i}, \ldots, \lambda_{t, K}^{i}\right)$ at date $t \geq 1$. Then the equilibrium relation between aggregate asset supply and demand implies the formula determining the equilibrium prices

$$
p_{t, k} V_{t, k}=\sum_{i=1}^{N} \lambda_{t, k}^{i} w_{t}^{i}, k=1, \ldots, K,
$$

of the risky assets. This, in turn, yields the expression for the investors' $i=$ $1, \ldots, N$ portfolios $x_{t}^{i}=\left(x_{t, 1}^{i}, \ldots, x_{t, K}^{i}\right)$ :

$$
\begin{gathered}
x_{t, k}^{i}=\frac{\lambda_{t, k}^{i} w_{t}^{i}}{p_{t, k}}, k=1, \ldots, K, \\
x_{t, 0}^{i}=\frac{\lambda_{t, 0}^{i} w_{t}^{i}}{p_{t, 0}}=\lambda_{t, 0}^{i} w_{t}^{i} .
\end{gathered}
$$

Here, in contrast with the case $t=0$, the traders' budgets at date $t \geq 1$ are not given exogenously as initial endowments, rather they are formed by the payoffs of the previous date's portfolios $x_{t-1}^{i}$.

Given a strategy profile $\left(\Lambda^{1}, \ldots, \Lambda^{N}\right)$ of the investors, we can generate a path of the market game by setting $\lambda_{0}^{i}=\Lambda_{0}^{i}, i=1, \ldots, N$,

$$
\lambda_{t}^{i}=\Lambda_{t}^{i}\left(s^{t}, \lambda^{t-1}\right), t=1,2, \ldots, i=1, \ldots, N,
$$

and by defining $p_{t}$ and $x_{t}^{i}$ recursively according to equations (7)-(12). The random dynamical system described determines the state of the market at each moment of time $t \geq 1$ as a measurable vector function of $s^{t}$ :

$$
\left(p_{t}\left(s^{t}\right) ; x_{t}^{1}\left(s^{t}\right), \ldots, x_{t}^{N}\left(s^{t}\right) ; \lambda_{t}^{1}\left(s^{t}\right), \ldots, \lambda_{t}^{N}\left(s^{t}\right)\right), t=0,1, \ldots
$$

where $p_{t}\left(s^{t}\right), x_{t}^{i}\left(s^{t}\right)$ and $\lambda_{t}^{i}\left(s^{t}\right)$ are the vectors of equilibrium prices, investors' portfolios and their investment proportions, respectively. (For $t=0$, these vectors are constant.) The sequence of random states (14) of the market forms the path of the dynamic game under consideration generated by the strategy profile $\left(\Lambda^{1}, \ldots, \Lambda^{N}\right)$.

A comment regarding the above description of asset market dynamics is in order. Portfolio positions $x_{t, k}^{i}$ are well-defined by the formula (11) only if the prices $p_{t, k}, k=1, . ., K$, are strictly positive, or equivalently, if the aggregate demand for each risky asset $k=1, \ldots, K$ is strictly positive:

$$
\sum_{i=1}^{N} \lambda_{t, k}^{i} w_{t}^{i}>0
$$


It is also important that

$$
\bar{w}_{t}=\sum_{i=1}^{N} x_{t, 0}^{i}=\sum_{i=1}^{N} \lambda_{t, 0}^{i} w_{t}^{i}>0
$$

for every $t \geq 0$, i.e. the aggregate demand $\sum_{i=1}^{N} \lambda_{t, 0}^{i} w_{t}^{i}$ for the risk-free asset $k=0$ is non-zero as well. Indeed, if $\bar{w}_{t}=\sum_{i=1}^{N} x_{t, 0}^{i}=0$, then $x_{t, 0}^{i}=0$ for each $i=1, \ldots, N$ and $A_{t+1, k}=a_{t+1, k} \bar{w}_{t}=0$ for all $k=1, \ldots, K$. Consequently,

$$
w_{t+1}^{i}=\left\langle A_{t+1}, x_{t}^{i}\right\rangle=\sum_{k=0}^{K} A_{t+1, k} x_{t, k}^{i}=\left(1+\beta_{t+1}\right) x_{t, 0}^{i}+\sum_{k=1}^{K} a_{t+1, k} \bar{w}_{t} x_{t, k}^{i}=0
$$

because $x_{t, 0}^{i}=\bar{w}_{t}=0$. Thus, if $\bar{w}_{t}=0$ for some time $t$, then at time $t+1$ the wealth $w_{t+1}^{i}$ of each investor $i=1, \ldots, N$ vanishes, and the market collapses.

Those strategy profiles for which the above recursive procedure generates non-zero aggregate demand for all $k=0,1, \ldots, K$ and $t \geq 0$, i.e. conditions (15) and (16) hold, will be called admissible. In what follows, we will deal only with strategy profiles satisfying this assumption. This assumption guarantees that the random dynamical system under consideration is well-defined, $\bar{w}_{t}>0$ and $p_{t, k}>0$ for all $t \geq 0$ and $k=1, \ldots, K$.

We provide a sufficient condition for a strategy profile to be admissible, which will hold for all the strategy profiles we consider in the present paper (it will follow from hypothesis (22) below). Assume that one of the traders, e.g., trader 1, employs a fully diversified portfolio rule, which prescribes investing into all assets in strictly positive proportions $\lambda_{t, k}^{1}>0$ for all $k=0,1, \ldots, K$ and all $t \geq 0$. By induction, we obtain

$$
w_{t}^{1}=\sum_{k=0}^{K} A_{t, k} x_{t-1, k}^{1} \geq A_{t, 0} x_{t-1,0}^{1}=\left(1+\beta_{t}\right) \lambda_{t-1,0}^{1} w_{t-1}^{1}>0,
$$

which in turn yields

$$
\bar{w}_{t}=\sum_{i=1}^{N} \lambda_{t, 0}^{i} w_{t}^{i} \geq \lambda_{t, 0}^{1} w_{t}^{1}>0
$$

and

$$
\sum_{i=1}^{N} \lambda_{t, k}^{i} w_{t}^{i} \geq \lambda_{t, k}^{1} w_{t}^{1}>0 \text { for } k=1, \ldots, K
$$

This shows that any strategy profile containing a fully diversified portfolio rule is admissible.

Assuming that the strategy profile under consideration is admissible and summing up equations (11) over $i=1, \ldots, N$, we find that

$$
\sum_{i=1}^{N} x_{t, k}^{i}=\frac{\sum_{i=1}^{N} \lambda_{t, k}^{i} w_{t}^{i}}{p_{t, k}}=\frac{p_{t, k} V_{t, k}}{p_{t, k}}=V_{t, k}, k=1, \ldots, K
$$


i.e., the market clears for every asset $k=1, \ldots, K$ and each date $t \geq 0$.

Finally, we note that one could give a seemingly more general definition of a strategy, assuming that the investors can use information not only about their own and their rivals' decisions, but also about the previous asset prices $p_{0}, \ldots, p_{t-1}$ and the portfolios $x_{l}^{i}, i=1, \ldots, N, l=0, \ldots, t-1$. But all these data are determined by the history $s^{t-1}$ of the states of the world and the investors' decisions $\left(\lambda_{l}^{i}\right), i=1, \ldots, N, l=0, \ldots, t-1$ up to time $t-1$. Therefore this broader definition does not lead, in fact, to a more general notion of a strategy.

\section{The Main Results}

Consider an admissible strategy profile $\left(\Lambda^{1}, \ldots, \Lambda^{N}\right)$ of the investors and the path (14) of the random dynamical system generated by this strategy profile. The sum

$$
W_{t}=\sum_{i=1}^{N} w_{t}^{i}
$$

where $w_{t}^{i}=\left\langle A_{t}, x_{t-1}^{i}\right\rangle$ is the wealth of investor $i=1, \ldots, N$, represents the total market wealth at date $t \geq 0$. We are primarily interested in the longrun behavior of the relative wealth, or the market shares, $r_{t}^{i}:=w_{t}^{i} / W_{t}$ of the traders, i.e., in the asymptotic properties of the sequence of vectors $r_{t}=$ $\left(r_{t}^{1}, \ldots, r_{t}^{N}\right)$ as $t \rightarrow \infty$. Note that the numbers $r_{t}^{i}, i=1,2, \ldots, N$, are well-defined since $W_{t} \geq \bar{w}_{t}>0$ as long as the strategy profile is admissible.

Given an admissible strategy profile $\left(\Lambda^{1}, \ldots, \Lambda^{N}\right)$, we say that the strategy $\Lambda^{i}$ (or investor $i$ using it) survives with probability one if

$$
\inf _{t \geq 0} r_{t}^{i}>0
$$

almost surely (a.s.). This means that for almost all realizations of the process of states of the world $\left(s_{t}\right)$, the market share of investor $i$ is bounded away from zero by a strictly positive random variable. A portfolio rule $\Lambda$ is called a survival strategy if investor $i$ using it survives with probability one regardless of what portfolio rules $\Lambda^{j}, j \neq i$, are used by the other investors.

To formulate the main results on survival strategies we define

$$
R_{t+1, k}=\frac{a_{t+1, k} V_{t, k}}{\sum_{l=0}^{K} a_{t+1, l} V_{t, l}}, k=0, \ldots, K,
$$

where

$$
a_{t+1,0}:=1+\beta_{t+1}, V_{t, 0}:=1 .
$$

Clearly,

$$
\sum_{k=0}^{K} R_{t+1, k}=1
$$


Consider the investment strategy $\Lambda^{*}=\left(\lambda_{t}^{*}\right)$ for which the vectors of investment proportions $\lambda_{t}^{*}=\left(\lambda_{t, 0}^{*}, \ldots, \lambda_{t, K}^{*}\right)$ are defined by

$$
\lambda_{t, k}^{*}\left(s^{t}\right):=E\left[R_{t+1, k}\left(s^{t+1}\right) \mid s^{t}\right] .
$$

Here, $E\left(\cdot \mid s^{t}\right)$ stands for the conditional expectation given $s^{t}$ (if $t=0$, then this is just the unconditional expectation $E(\cdot))$. The strategy $\Lambda^{*}$ prescribes to distribute wealth according to the proportions of the conditional expectations of the relative asset payoffs.

Assume that for each $k=0,1,2, \ldots, K$,

$$
E \ln E_{t} R_{t+1, k}\left(s^{t+1}\right)>-\infty .
$$

This assumption implies that the conditional expectation $E_{t} R_{t+1, k}=$ $E\left(R_{t+1, k} \mid s^{t}\right)$ is strictly positive a.s., and so we can select a version of this conditional expectation that is strictly positive for all $s^{t}$. This version will be used in the definition (21) of the portfolio rule $\Lambda^{*}=\left(\lambda_{t}^{*}\right)$.

A central result is as follows.

Theorem 1. The portfolio rule $\Lambda^{*}$ is a survival strategy.

Note that the portfolio rule $\Lambda^{*}$ belongs to the class of basic portfolio rules: the investment proportions $\lambda_{t}^{*}\left(s^{t}\right)$ depend only on the history $s^{t}$ of the process of states of the world, and do not depend on the market history. The following theorem shows that in this class the survival strategy $\Lambda^{*}=\left(\lambda_{t}^{*}\right)$ is essentially unique: any other basic survival strategy is asymptotically similar to $\Lambda^{*}$.

Theorem 2. If $\Lambda=\left(\lambda_{t}\right)$ is a basic survival strategy, then

$$
\sum_{t=0}^{\infty}\left\|\lambda_{t}^{*}-\lambda_{t}\right\|^{2}<\infty \text { (a.s.). }
$$

Here, the symbol " $\|\cdot\| "$ stands for any norm in a finite-dimensional linear space. Theorem 2 is akin to various turnpike results in the theory of economic growth, expressing the idea that all optimal or "quasi-optimal" paths of an economic system incline in the long run to essentially the same route: the turnpike (Nikaido [56], McKenzie [52], Arkin and Evstigneev [4]). Survival portfolio rules $\Lambda$ can be characterized by the property that the wealth $w_{t}^{j}$ of any investor $j$ cannot grow asymptotically faster with strictly positive probability than the wealth of investor $i$ using $\Lambda$ (see [3], Section 6). The class of such portfolio rules is similar to the class of "good" paths of economic dynamics, as introduced by Gale [28] — paths that cannot be "infinitely worse" than the turnpike. Theorem 2 is a direct counterpart of Gale's turnpike theorem for good paths (Gale [28], Theorem 8); a stochastic version of this result is established in Arkin and Evstigneev [4], Chapter 4, Theorem 6. 


\section{Appendix}

To prove Theorems 1 and 2 we derive a random dynamical system describing the dynamics of the market shares $r_{t}^{i}$ of the investors $i=1, \ldots, N$.

Theorem 3. The following equations hold:

$$
r_{t+1}^{i}=\sum_{k=0}^{K} R_{t+1, k} \frac{\lambda_{t, k}^{i} r_{t}^{i}}{\left\langle\lambda_{t, k}, r_{t}\right\rangle}, t=0,1,2, \ldots, i=1,2, \ldots, N .
$$

Proof. Put

$$
\bar{V}_{t, 0}:=\bar{w}_{t}\left[=\sum_{i=1}^{N} x_{t, 0}^{i}=\sum_{i=1}^{N} \lambda_{t, 0}^{i} w_{t}^{i}\right], \bar{V}_{t, k}=V_{t, k}, k=1,2, \ldots, K .
$$

By using the notation $A_{t+1,0}=1+\beta_{t+1}$, we write

$$
\begin{gathered}
W_{t+1}=\sum_{i=1}^{N} w_{t+1}^{i}=\sum_{i=1}^{N}\left\langle A_{t+1}, x_{t}^{i}\right\rangle=\sum_{i=1}^{N} \sum_{k=0}^{K} A_{t+1, k} x_{t, k}^{i} \\
=\sum_{k=0}^{K}\left(A_{t+1, k} \sum_{i=1}^{N} x_{t, k}^{i}\right)=\left(1+\beta_{t+1}\right) \bar{w}_{t}+\sum_{k=1}^{K} A_{t+1, k} V_{t, k}=\sum_{k=0}^{K} A_{t+1, k} \bar{V}_{t, k} .
\end{gathered}
$$

Define $\lambda_{t, k}:=\left(\lambda_{t, k}^{1}, \ldots, \lambda_{t, k}^{N}\right)$ and $w_{t}:=\left(w_{t}^{1}, \ldots, w_{t}^{N}\right)$. From (7) and (10) we get

$$
p_{t, k} V_{t, k}=\left\langle\lambda_{t, k}, w_{t}\right\rangle, k=1, \ldots, K, t \geq 0,
$$

which implies

$$
x_{t, k}^{i}=\frac{\lambda_{t, k}^{i} w_{t}^{i}}{p_{t, k}}=\frac{\lambda_{t, k}^{i} w_{t}^{i} V_{t, k}}{\left\langle\lambda_{t, k}, w_{t}\right\rangle}=\frac{\lambda_{t, k}^{i} w_{t}^{i} \bar{V}_{t, k}}{\left\langle\lambda_{t, k}, w_{t}\right\rangle}, k=1, \ldots, K, t \geq 0
$$

(see 11). Further, we find

$$
p_{t, 0} \bar{V}_{t, 0}=\bar{V}_{t, 0}=\bar{w}_{t}=\left\langle\lambda_{t, 0}, w_{t}\right\rangle,
$$

where the first equality holds because $p_{t, 0}=1$, the second follows from (25), and the third is a consequence of (1) and (12). By using (12) and (12), we obtain

$$
x_{t, 0}^{i}=\frac{\lambda_{t, 0}^{i} w_{t}^{i}}{p_{t, 0}}=\frac{\lambda_{t, 0}^{i} w_{t}^{i} \bar{V}_{t, 0}}{\left\langle\lambda_{t, 0}, w_{t}\right\rangle} .
$$

From (29) and (27) we get

$$
\begin{aligned}
w_{t+1}^{i}=\sum_{k=0}^{K} A_{t+1, k} x_{t, k}^{i} & =A_{t+1,0} \bar{V}_{t, 0} \frac{\lambda_{t, 0}^{i} w_{t}^{i}}{\left\langle\lambda_{t, 0}, w_{t}\right\rangle}+\sum_{k=1}^{K} A_{t+1, k} \bar{V}_{t, k} \frac{\lambda_{t, k}^{i} w_{t}^{i}}{\left\langle\lambda_{t, k}, w_{t}\right\rangle} \\
& =\sum_{k=0}^{K} A_{t+1, k} \bar{V}_{t, k} \frac{\lambda_{t, k}^{i} w_{t}^{i}}{\left\langle\lambda_{t, k}, w_{t}\right\rangle} .
\end{aligned}
$$


Dividing the first and the last terms in this chain of equalities by $W_{t+1}$ and using (26), we get

$$
r_{t+1}^{i}=\sum_{k=0}^{K} \frac{A_{t+1, k} \bar{V}_{t, k}}{\sum_{l=0}^{K} A_{t+1, l} \bar{V}_{t, l}} \frac{\lambda_{t, k}^{i} w_{t}^{i}}{\left\langle\lambda_{t, k}, w_{t}\right\rangle} .
$$

Observe that

$$
\frac{\lambda_{t, k}^{i} w_{t}^{i}}{\left\langle\lambda_{t, k}, w_{t}\right\rangle}=\frac{\lambda_{t, k}^{i} w_{t}^{i} / W_{t}}{\left\langle\lambda_{t, k}, w_{t} / W_{t}\right\rangle}=\frac{\lambda_{t, k}^{i} r_{t}^{i}}{\left\langle\lambda_{t, k}, r_{t}\right\rangle}
$$

Further, we have

$$
\begin{gathered}
\frac{A_{t+1, k} \bar{V}_{t, k}}{\sum_{l=0}^{K} A_{t+1, l} \bar{V}_{t, l}}=\frac{a_{t+1, k} \bar{w}_{t} \bar{V}_{t, k}}{\left(1+\beta_{t+1}\right) \bar{w}_{t}+\sum_{l=1}^{K} a_{t+1, l} \bar{w}_{t} \bar{V}_{t, l}} \\
=\frac{a_{t+1, k} V_{t, k}}{\sum_{l=0}^{K} a_{t+1, l} V_{t, l}}=R_{t+1, k}
\end{gathered}
$$

$(k=1, \ldots, K)$ and

$$
\begin{gathered}
\frac{A_{t+1,0} \bar{V}_{t, 0}}{\sum_{l=0}^{K} A_{t+1, l} \bar{V}_{t, l}}=\frac{\left(1+\beta_{t+1}\right) \bar{w}_{t}}{\left(1+\beta_{t+1}\right) \bar{w}_{t}+\sum_{l=1}^{K} a_{t+1, l} \bar{w}_{t} V_{t, l}} \\
=\frac{a_{t+1,0} V_{t, 0}}{\sum_{l=0}^{K} a_{t+1, l} V_{t, l}}=R_{t+1,0}
\end{gathered}
$$

(see (18) and (19)). By substituting (31)-(33) into (30), we arrive at (24).

The proof is complete.

We have shown that the dynamics of the market shares $r_{t}^{i}$ of the investors $i=1,2, \ldots, N$, in the model at hand is governed by the random dynamical system (24). A detailed analysis of this system was carried out in Amir et al. [3]. Theorems 1 and 2 are direct consequences of Theorems 4 and 5 proved in Amir et al. [3], which we formulate below.

Let $R_{t, k}\left(s^{t}\right) \geq 0(t=0,1,2, \ldots ; k=0, \ldots, K)$ be measurable real-valued functions satisfying (20) and (22). Consider sequences of measurable vector functions $\Lambda=\left(\lambda_{t}\left(s^{t}\right)\right)_{t=0}^{\infty}$, where $\lambda_{t}\left(s^{t}\right)=\left(\lambda_{t, 0}\left(s^{t}\right), \ldots, \lambda_{t, K}\left(s^{t}\right)\right) \in \Delta^{K+1}$. Denote by $\mathcal{L}$ the set of $N$-tuples $\left(\Lambda^{1}, \ldots, \Lambda^{N}\right)$ of such sequences for which the random dynamical system (24) generates well-defined vectors $r_{t}^{i}=\left(r_{t, 0}^{i}, \ldots, r_{t, K}^{i}\right) \in$ $\Delta^{K+1}, i=1, \ldots, N, t=0,1, \ldots$, i.e., the validity of the inequality

$$
\sum_{i=1}^{N} \lambda_{t, k}^{i} r_{t}^{i}>0, k=0,1, \ldots, K
$$

is guaranteed for each $t \geq 0$. Define $\Lambda^{*}=\left(\lambda_{t}^{*}\left(s^{t}\right)\right)_{t=0}^{\infty}$ by $(21)$.

Theorem 4. For each $\left(\Lambda^{1}, \ldots, \Lambda^{N}\right) \in \mathcal{L}$ with $\Lambda^{1}=\Lambda^{*}$, we have $\inf _{t \geq 0} r_{t}^{1}>$ 0 (a.s.).

Theorem 5. Let $\Lambda=\left(\lambda_{t}\left(s^{t}\right)\right)_{t=0}^{\infty}$ be a sequence of measurable vector functions with values in $\Delta^{K+1}$. If $\inf _{t \geq 0} r_{t}^{1}>0$ for any $\left(\Lambda^{1}, \ldots, \Lambda^{N}\right) \in \mathcal{L}$ with $\Lambda^{1}=\Lambda$, then (23) holds.

For proofs of Theorems 4 and 5 see Amir et al. [3], Section 4. 


\section{References}

1. Algoet, P.H., and Cover, T.M. (1988). Asymptotic optimality and asymptotic equipartition properties of log-optimum investment. Annals of Probability 16(2), 876-898.

2. Amir, R., Evstigneev, I.V., Hens, T., and Xu, L. (2011). Evolutionary finance and dynamic games. Mathematics and Financial Economics 5, 161-184

3. Amir, R., Evstigneev, I.V., and Schenk-Hoppé, K.R. (2013). Asset Market Games of Survival: A Synthesis of Evolutionary and Dynamic Games. Annals of Finance 9(2), 121-144.

4. Arkin, V. I., and Evstigneev I. V. (1987). Stochastic Models of Control and Economic Dynamics. London: Academic Press.

5. Bachmann, K.K., De Giorgi, E.G., and Hens, T. (2018). Behavioral Finance for Private Banking: From the Art of Advice to the Science of Advice. Wiley Finance. 2nd Edition.

6. Benninga, S., Björk, T., and Wiener, Z. (2002). On the use of numeraires in option pricing. The Journal of Derivatives 10, 43-58.

7. Björk, T. (1999). Arbitrage Theory in Continuous Time. Oxford: Oxford University Press.

8. Borch, K. (1966). A utility function derived from a survival game. Management Science $12,287-295$.

9. Bottazzi, G., and Dindo, P. (2013). Evolution and market behavior in economics and finance: Introduction to the special issue. Journal of Evolutionary Economics 23, 507512.

10. Bottazzi, G., and Dindo, P. (2013). Selection in asset markets: the good, the bad, and the unknown. Journal of Evolutionary Economics 23, 641-661.

11. Bottazzi, G., Dindo, P., and Giachini, D. (2018). Long-run heterogeneity in an exchange economy with fixed-mix traders. Economic Theory 66, 407-447.

12. Bottazzi, G., Dosi, G., and Rebesco, I. (2005). Institutional architectures and behavioral ecologies in the dynamics of financial markets. Journal of Mathematical Economics 41 $197-228$.

13. Breiman, L. (1961). Optimal gambling systems for favorable games. Proceedings of the Fourth Berkeley Symposium on Mathematical Statistics and Probability 1, 65-78.

14. Brock, A.W., Hommes, C.H., and Wagener, F.O.O. (2005). Evolutionary dynamics in markets with many trader types. Journal of Mathematical Economics 41 (Special Issue on Evolutionary Finance), 7-42.

15. Cabrales, A. (2000). Stochastic replicator dynamics. International Economic Review $41,451-481$.

16. Cover, T.M. (1998). Shannon and investment. IEEE Information Theory Society Newsletter, Summer, Special Golden Jubilee Issue, 10-11.

17. Coury, T., and Sciubba, E. (2012). Belief heterogeneity and survival in incomplete markets. Economic Theory, 49, 37-58.

18. Dempster, M.A.H., Evstigneev, I.V., and Schenk-Hoppé, K.R. (2007). Volatility-induced financial growth. Quantitative Finance 7, 151-160.

19. Dynkin, E. B. (1969) Game variant of a problem on optimal stopping. Soviet Mathematics Doklady 10, 270-274.

20. Evstigneev, I.V., Hens, T., and Schenk-Hoppé, K.R. (2009). Evolutionary finance. Handbook of Financial Markets: Dynamics and Evolution (T. Hens and K.R. Schenk-Hoppé, eds.), Chapter 9. Amsterdam: Elsevier, 507-566.

21. Evstigneev, I.V., Hens, T., and Schenk-Hoppé, K.R. (2011). Local stability analysis of a stochastic evolutionary financial market model with a risk-free asset. Mathematics and Financial Economics 5, 185-202.

22. Evstigneev, I.V., Hens, T., and Schenk-Hoppé, K.R. (2015). Mathematical Financial Economics: A Basic Introduction. Springer.

23. Evstigneev, I.V., Hens, T., and Schenk-Hoppé, K.R. (2016). Evolutionary behavioural finance. Handbook of Post Crisis Financial Modelling (E. Haven et al., eds.), Palgrave MacMillan, 214-234.

24. Farmer, J.D. (2002). Market force, ecology and evolution. Industrial and Corporate Change 11, 895-953. 
25. Farmer, J.D. and Lo, A.W. (1999). Frontiers of finance: Evolution and efficient markets, Proceedings of the National Academy of Sciences of the USA 96, 9991-9992.

26. Foster, D., and Young P. (1990). Stochastic evolutionary game dynamics. Theoretical Population Biology 38, 219-232.

27. Fudenberg, D., and Harris, C. (1992). Evolutionary dynamics with aggregate shocks. Journal of Economic Theory 57, 420-441.

28. Gale, D. (1967). On optimal development in a multi-sector economy. Review of Economic Studies 34, 1-18.

29. Geman, H., El Karoui, N., and Rochet, J.C. (1995). Change of Numeraire, Changes of Probability Measures and Pricing of Options. Journal of Applied Probability 32, 443458.

30. Germano, F. (2007). Stochastic evolution of rules for playing finite normal form games. Theory and Decision 62(4), 311-333.

31. Gintis, H. (2009). Game Theory Evolving: A Problem-Centered Introduction to Modeling Strategic Interaction, Second Edition, Princeton University Press.

32. Hakansson, N.H., and Ziemba, W.T. (1995). Capital growth theory. Handbooks in Operations Research and Management Science (R.A. Jarrow et al., eds.), Amsterdam: Elsevier, 65-86.

33. Harrison, J., and Kreps, J. (1981). Martingales and Arbitrage in Multiperiod Securities Markets. Journal of Economic Theory 11, 418-443.

34. Haurie, A., Zaccour, G., and Smeers, Y. (1990). Stochastic equilibrium programming for dynamic oligopolistic markets. Journal of Optimization Theory and Applications $66,243-253$.

35. Hofbauer, J., and Sigmund, K. (1998). Evolutionary Games and Population Dynamics. Cambridge, UK: Cambridge University Press.

36. Karni, E., and Schmeidler, D. (1986). Self-preservation as a foundation of rational behavior under risk. Journal of Economic Behavior and Organization 7, 71-81.

37. Kelly, J.L. (1956). A new interpretation of information rate. Bell System Technical Journal 35(4), 917-926.

38. Kifer, Y. (2000). Game options. Finance and Stochastics 4, 443-463.

39. Kojima, F. (2006). Stability and instability of the unbeatable strategy in dynamic processes. International Journal of Economic Theory 2, 41-53.

40. Kuhn, D., and Luenberger, D.G. (2010). Analysis of the rebalancing frequency in logoptimal portfolio selection. Quantitative Finance 10, 221-234.

41. Latané, H. (1959). Criteria for choice among risky ventures. Journal of Political Economy $67,144-155$.

42. Lintner, J. (1965). The valuation of risk assets and the selection of risky investments in stock portfolios and capital budgets. Review of Economics and Statistics 47(1), 13-37.

43. Lo, A.W. (2004). The Adaptive Markets Hypothesis: Market efficiency from an evolutionary perspective. The Journal of Portfolio Management 30, 15-29.

44. Lo, A.W. (2005). Reconciling Efficient Markets with Behavioral Finance: The Adaptive Market Hypothesis. Journal of Investment Consulting 7, 21-44.

45. Lo, A.W. (2012). Adaptive Markets and the New World Order. Financial Analyst Journal $68,18-29$.

46. Lo, A.W. (2017). Adaptive Markets: Financial Evolution at the Speed of Thought. Princeton University Press.

47. Lo, A.W., Orr, H.A., and Zhang, R. (2018). The growth of relative wealth and the Kelly criterion. Journal of Bioeconomics 20, 49-67.

48. Luenberger, D. (1998). Investment Science. Oxford University Press, New York.

49. MacLean, L.C., Thorp, E.O., and Ziemba, W.T., eds. (2011). The Kelly Capital Growth Investment Criterion: Theory and Practice. Singapore: World Scientific.

50. MacLean, L.C., and Ziemba, W.T., eds. (2013). Handbook of the Fundamentals of Financial Decision Making. Singapore: World Scientific.

51. Markowitz, H.M. (1952). Portfolio Selection. Journal of Finance. 7(1): 77-91.

52. McKenzie, L. W. (1986). Optimal economic growth, turnpike theorems and comparative dynamics. Handbook of Mathematical Economics III (K.J. Arrow and M. D. Intrilligator, eds.), Amsterdam: North-Holland, 1281-1355. 
53. Milnor, J., and L. S. Shapley (1957). On games of survival. Contributions to the Theory of Games III, Annals of Mathematical Studies 39 (M. Dresher et al., eds.). Princeton, NJ: Princeton University Press, 15-45.

54. Mossin, J. (1966). Equilibrium in a Capital Asset Market. Econometrica 34(4), 768-783.

55. Neyman, A., and Sorin, S., eds. (2003). Stochastic Games and Applications, NATO ASI series. Dordrecht: Kluwer Academic Publishers.

56. Nikaido, H. (1968). Convex Structures and Economic Theory. New York: Academic Press.

57. Samuelson, L. (1997). Evolutionary Games and Equilibrium Selection. Cambridge, MA: MIT Press.

58. Sciubba, E. (2005). Asymmetric information and survival in financial markets. Economic Theory 25, 353-379.

59. Sciubba, E. (2006). The evolution of portfolio rules and the capital asset pricing model. Economic Theory 29, 123-150.

60. Shannon, C. (1956). Lectures on investment problems. MIT (unpublished). ${ }^{1}$

61. Shapley, L. S. (1953). Stochastic games. Proceedings of the National Academy of Sciences of the USA 39, 1095-1100.

62. Sharpe, W.F. (1964). Capital asset prices: A theory of market equilibrium under conditions of risk. Journal of Finance 19(3), 425-442.

63. Shiller, R. J. (2003). From efficient markets theory to behavioral finance. Journal of Economic Perspectives 17(1), 83-104.

64. Shleifer, A. (2000). Inefficient Markets: An Introduction to Behavioral Finance. Oxford, UK: Oxford University Press.

65. Shubik, M., and Thompson, G. (1959). Games of economic survival. Naval Research Logistics Quarterly 6, 111-123.

66. Thaler, R. H., ed. (2005). Advances in Behavioral Finance II. Princeton, NJ: Princeton University Press.

67. Tobin, J. (1958). Liquidity preference as behavior towards risk. Review of Economic Studies, 25(2), 65-86.

68. Tversky, A., and Kahneman, D. (1991). Loss aversion in riskless choice: A referencedependent model. Quarterly Journal of Economics 106, 1039-1061.

69. Vega-Redondo, F. (1996). Evolution, Games, and Economic Behavior. Oxford, UK: Oxford University Press.

70. Vieille, N. (2000). Two-player stochastic games I: A reduction. Israel Journal of Mathematics 119(1), 55-91.

71. Vieille, N. (2000). Two-player stochastic games II: The case of recursive games. Israel Journal of Mathematics 119(1), 93-126.

72. Vieille, N. (2000). Small perturbations and stochastic games. Israel Journal of Mathematics 119(1), 127-142.

73. Weibull, J. (1995). Evolutionary Game Theory. Cambridge, MA: MIT Press.

74. Zhang, R., Brennan, T.J., and Lo, A.W. (2014). Group Selection as Behavioral Adaptation to Systematic Risk. PLOS ONE 9, 1-9.

75. Ziemba, W.T., and Vickson, R.G. (2011). Models of optimal capital accumulation and portfolio selection and the capital growth criterion. The Kelly Capital Growth Investment Criterion: Theory and Practice (MacLean, L.C., et al., eds), Singapore: World Scientific, 473-485.

\footnotetext{
1 See Cover [16].
} 